committee, but nobody should be surprised if the outcome is a lot of hard and often tedious work. If the result is to create in Europe a still more alert and vigorous intellectual community, the trouble will be well worth while.

\section{SMOKE WITHOUT FIRE}

NoBODy should be surprised or even cast down that the symposium on science policy at Edinburgh last week failed to decide what constitutes the science of science. At the best, it is a will o' the wisp, worth chasing for fun now and again, but not the stuff of which academic disciplines are made. One difficulty, perhaps unimportant, is the name, which raises all kinds of red herrings. There is plenty of sport to be had in coining names such as the economics of economics or even the science of the science of science, but it is particularly sad that the grandiose but alliterative title now sometimes in fashion seems to work on the belief that if science itself is good, then a double dose must be better. The real trouble, of course, is the implicit suggestion that the study of how science functions and how it interacts with other kinds of intellectual activity is itself a self-sustaining field of study. The truth is quite different. If the study has meaning of any kind in strictly academic terms, it is fully and inevitably interdisciplinary. All kinds of people-economists, sociologists, historians and even natural scientists-have much to contribute. But because of the concern in many countries, advanced and otherwise, self-consciously to apply science and technology to industrial and economic growth, it is natural that the economists should make the running, but there is also plenty of scope for those concerned with the handling of information, the nature of creativity and the organization of research and of academic life. It is no surprise and no disappointment. that the subject does not hang together. To try to make it do so by artifice would be a great mistake.

This said, there is no reason to fear that the units of various kinds which have been established at universities in Britain and elsewhere, and which are devoted to particular aspects of the scientific process, are also mistakes. On the contrary, many of them promise to be valuable embellishments of academic life and revealing educational experiments as well. The unit at Edinburgh has been careful to fight shy of anything like a commitment to over-solemn doctrines, and is seeking to broaden the vision of undergraduates in science subjects by a battery of intellectual stimuli chosen empirically. At other universities, as at the University of Sussex, the principal objective is research, much of it economic. Then the universities of Manchester and Stirling are designing courses of study for undergraduates intended to weave together economics, technology and science in novel ways. These innovations are valuable experiments, and deserve to prosper. To do so, they must avoid cant and cliché like the plague.

\section{NEWS AND VIEWS}

\section{European Physicists United ?}

A Powerful move to create a European physical society was made by the first European Conference on Controlled Fusion and Plasma Physics, meeting at Munich in October. In a statement issued on October 10, the members of the conference expressed their "urgent wish to promote the establishment of a European physical society". The statement goes on to say that the society should be chiefly concerned "with enlarging the possibilities of discussions and personal contact among European physicists and with promoting the co-ordination of European physical research by the organization of European physical conferences and with the publication of the results of European physical research". The conference at Munich appointed a committee to shoulder responsibility for keeping in touch with national physical societies in Europe in the hope of organizing an annual meeting of physicists along the lines of the meetings organized by the American Physical Society. The members of the committee are Prof. Bruno Brunelli, Laboratorio, Frascati; Prof. H. G. Van Bueren. Instituut voor Plasma-Fysica, Rijnhuizen, Jutphaas, Netherlands; Dr. Bo Lehnert, Royal Institute of Technology, Stockholm; Prof. A. Schluter, Institut fur Plasmaphysik, Garching bei Munchen, FDR; Dr. P. C. Thonemann, Culham Laboratory, Abingdon; Dr. M. Trocheris, Centre d'Etude Nucleaires, Fontenay-auxRoses; and Prof. P. Vandenplas, Ecole Royale Militaire, Brussels.

The suggestion by the plasma physicists follows closely on a similar move by a group of high-energy physicists. An informal meeting at which several European physical societies will be informally represented is to be held at Geneva later this month. chiefly through the initiative of Prof. G. Bernadini. and it is thought that a draft constitution will then be put forward as a basis for more formal discussions. These and other initiatives appear to have been received favourably in several European countries. In London, for example, the council of the Physical Society and the Institute of Physics decided at its last meeting early in October that a European physical society would in principle be welcome. It is, however, recognized that the character of such a society cannot be determined until there has been full discussion among national physical societies.

\section{Lords on Cow Green}

THe interest aroused by the proposal of the Tees Valley and Cleveland Water Board to build a reservoir in Upper Teesdale was shown by the presence of no fewer than twenty-six members of the House of Lords on the list to speak on the Second Reading on Tuesday. Lord Lindgren, moving the second reading, said that the building of a reservoir to serve Tees-side was a matter of urgency. The site at Cow Green had been selected after encouragement by the Nature Conservancy, which had since changed its mind, but it was foolish not to admit that there were alternative sites. Consideration by a 